\title{
Urinary Neopterin Concentrations vs Total Neopterins for Clinical Utility
}

\author{
Dietmar Fuchs, ${ }^{1}$ Sheldon Mllstien, ${ }^{2}$ Alexander Krämer, ${ }^{3}$ Gllbert Relbnegger, ${ }^{1}$ Ernst R. Werner, ${ }^{1}$ James J. Goedert, ${ }^{3}$ Seymor \\ Kautman, ${ }^{2}$ and Helmut Wachter 1,4
}

Neopterin measurements are especially useful as an early marker in (e.g.) allograft rejections and in patients infected with human immunodeficiency virus type 1 (HIV-1). An increased concentration of total neopterins (neopterin + dihydroneopterin) is also a significant marker in patients with HIV-1 infection. In this study we compared concentrations of neopterin and total neopterins in urine samples from 77 homosexual men with and 73 without established HIV-1 infection. HIV-1-seropositive homosexual men had higher concentrations of neopterin and total neopterins (and 7,8dihydroneopterin) in their urine than did those who were HIV-1-seronegative, and there was a close correlation between neopterin and total neopterins. Both neopterin variables correlated inversely with $\mathrm{CD}^{+}{ }^{+}$T-cell counts and $\mathrm{CD}^{+} /$ $\mathrm{CD8}^{+} \mathrm{T}$-cell ratios but not with $\mathrm{CD8}^{+} \mathrm{T}$-cell counts in the HIV-1-seropositive men. Our data indicate that measurements of neopterin and total neopterins are of almost equal potential for clinical diagnosis. However, when measuring total neopterins, which includes oxidation of 7,8-dihydroneopterin to neopterin, more strict requirements of sample collection and handling are necessary to avoid degradation of the 7,8-dihydro derivative.

Additional Keyphrases: dihydroneopterin - urine - human immunodeficiency virus - T-cell subpopulation - acquired immune deficiency syndrome

7,8-Dihydroneopterin triphosphate is the first intermediate on the de novo biosynthetic pathway from guanosine triphosphate to 5,6,7,8-tetrahydrobiopterin (1), the cofactor of the monooxygenases phenylalanine-4-monooxygenase (EC 1.14.16.1), tyrosine-3-monooxygenase (EC 1.14.16.2), and tryptophan-5-monooxygenase (EC 1.14.16.4) $(2,3)$. Inborn deficiency of tetrahydrobiopterin is known as an atypical form of phenylketonuria.

Recently it has been shown that concentrations of 6D-erythro-trihydroxypropylpterin (neopterin), a metabolite of dihydroneopterin triphosphate, are an indicator of cellular immune response in humans. Neopterin measurements provide important information in several disease states (4, 5) and are especially useful as an early marker in allograft

\footnotetext{
${ }^{1}$ Institute of Medical Chemistry and Biochemistry, University of Innsbruck and Ludwig Boltzmann Institute of AIDS Research, Innsbruck, Austria.

2 Department of Neurochemistry, National Institute of Mental Health, Bethesda, MD 20892.

${ }^{3}$ Viral Epidemiology Section, National Cancer Institute, Bethesda, MD 20892.

${ }^{4}$ Address correspondence to this author: Institute of Medical Chemistry and Biochemistry, University of Innsbruck, Fritz Pregl Strasse 3, A-6020 Innsbruck, Austria.

Received May 30, 1989; accepted August 4, 1989.
}

rejections and infectious complications in graft recipients. Neopterin concentrations parallel disease activity and reveal predictive information-about autoimmune disease such as rheumatoid arthritis and systemic lupus erythematosus, about cancer, and about infectious diseases. Neopterin testing also may be valuable in evaluating patients infected with human immunodeficiency virus type I (HIV1) $(4-8)$.

The utility of the neopterin test in clinical settings has been investigated mostly by direct measurement of neopterin in body fluids (5-9). Neopterin is formed from 7,8dihydroneopterin by as-yet-uncharacterized oxidation reactions; dihydroneopterin is produced by dephosphorylation of dihydroneopterin triphosphate in body fluids. An increased concentration of total neopterins (i.e., neopterin + dihydroneopterin) has also been shown to be a significant marker in patients with HIV-1 infection $(8,10)$.

In this study we quantified concentrations of neopterin and total neopterins in urine samples from homosexual men with and without established HIV-1 infection. The significance of neopterin data was compared with analyses of T-cell subpopulations.

\section{Patlents and Methods}

Patients: A cohort of 150 homosexual men was investigated, including 69 who were anti-HIV-1 seropositive without AIDS and eight who had AIDS at the time of specimen collection (for a detailed description of the subjects, see refs. 8 and 11). HIV-1 antibodies were determined by a commercial ELSA (Electronucleonics Inc., Columbia, MD) with Western blot confirmation (Biotech Inc., Rockville, MD). Whole-blood samples for T-cell subset quantification and urines were collected at the same visit. Urine samples were frozen at $-20^{\circ} \mathrm{C}$ until measurement of neopterin, total neopterins, and creatinine by the two different laboratories $(3,4)$.

Quantification of neopterin: Concentrations of neopterin were quantified by direct measurement without oxidative pretreatment of samples as described (7), briefly as follows. We diluted $100 \mu \mathrm{L}$ of urine with $1 \mathrm{~mL}$ of Sørensen's potassium phosphate buffer $(15 \mathrm{mmol} / \mathrm{L}, \mathrm{pH} \mathrm{6.4)}$ and injected $10 \mu \mathrm{L}$ of this onto $125 \times 4 \mathrm{~mm} \mathrm{C} \mathrm{C}_{18}$ reversed-phase columns (LiChroCart; Merck, Darmstadt, F.R.G.) at $25^{\circ} \mathrm{C}$. Compounds were eluted at a flow rate of $0.8 \mathrm{~mL} / \mathrm{min}$. Neopterin was monitored by its native fluorescence (353 $\mathrm{nm}$ excitation, $438 \mathrm{~nm}$ emission). To account for physiological variations in urine excretion, we related neopterin concentrations to urinary creatinine concentrations, which were quantified in the same chromatographic run by measuring the absorbance at $235 \mathrm{~nm}$.

Quantification of total neopterins: Concentrations of total neopterins were quantified as described previously (12). Urine $(10 \mu \mathrm{L})$ was added to $190 \mu \mathrm{L}$ of $0.2 \mathrm{~mol} / \mathrm{L} \mathrm{H}_{3} \mathrm{PO}_{4}$ 
reagent, followed by $10 \mathrm{mg}$ of manganese dioxide $\left(\mathrm{MnO}_{2}\right)$. After they were mixed and left standing for $10 \mathrm{~min}$ at room temperature, the samples were centrifuged and the supernates were filtered. For HPLC analysis, $10 \mu \mathrm{L}$ was injected onto $\mathrm{C}_{18}$ reversed-phase columns (Partisil 10- $\mu \mathrm{m}$ particles, ODS-2; Whatman, Clifton, NJ) and the effluent was monitored by a fluorescence detector (Type 121; Gilson Medical Electronics, Villiers-Le Bel, France). The eluent was methanol/water $(5 / 95$ by vol) at a flow rate of $1.0 \mathrm{~mL} / \mathrm{min}$. The HPLC system consisted of a Model 6000 HPLC pump and WISP automatic sample injector (both from Waters Associates, Milford, MA), and a CR-1A recording integrator (Shimadzu, Kyoto, Japan). Creatinine concentrations were measured with a commercially supplied colorimetric assay (cat. no. 555; Sigma Chemical Co., St. Louis, MO).

Concentrations of 7,8-dihydroneopterin: Manganese dioxide oxidizes 7,8-dihydroneopterin to neopterin. We therefore calculated the concentration of 7,8-dihydroneopterin as the difference between total neopterins and neopterin (all values adjusted for creatinine excretion). Results were expressed as micromoles of 7,8-dihydroneopterin per mole of creatinine.

Quantification of T-cell subpopulations: T-cell subsets were measured in frozen/thawed lymphocytes with a fluorescence-activated cell sorter and monoclonal antibodies OKT4 and OKT8 (Ortho Diagnostics Co., Raritan, NJ) as measures of $\mathrm{CD4}^{+}-\mathrm{T}$-helper and $\mathrm{CD8}^{+}-\mathrm{T}$-suppressor subsets, respectively. The $\mathrm{CD}^{+}$and $\mathrm{CD}^{+} \mathrm{T}$-cell counts were defined as the total peripheral blood lymphocyte count multiplied by the proportion of mononuclear cells stained by OKT4 or OKT8.

Statistics: For comparison of grouped data we used the Kruskal-Wallis test. For assessing correlations between variables we applied the Spearman rank statistic.

\section{Results}

Concentrations of total neopterins in urine were about fourfold that of neopterin in the HIV-1-seronegative and -seropositive individuals (Table 1). The ratio of 7,8-dihydroneopterin (total neopterins minus neopterin) to neopterin is therefore about 3:1. Only in a few samples were larger ratios seen; e.g., in one HIV-1-seropositive man, total neopterins were $448 \mu \mathrm{mol}$ per mole of creatinine, only marginally higher than neopterin (427 $\mu \mathrm{mol}$ per mole of creatinine). In contrast, one HIV-1-seropositive man had $\sim 16$-fold more total neopterins (6070 $\mu \mathrm{mol}$ per mole of creatinine) than neopterin (353 $\mu \mathrm{mol}$ per mole of creatinine; Figure 1).

The HIV-1-seropositive men had higher concentrations of neopterin and total neopterins (and 7,8-dihydroneopterin) in their urine than did the HIV-1-seronegative men. AIDS patients had the highest concentrations (Table 1).

There was a close correlation between neopterin and

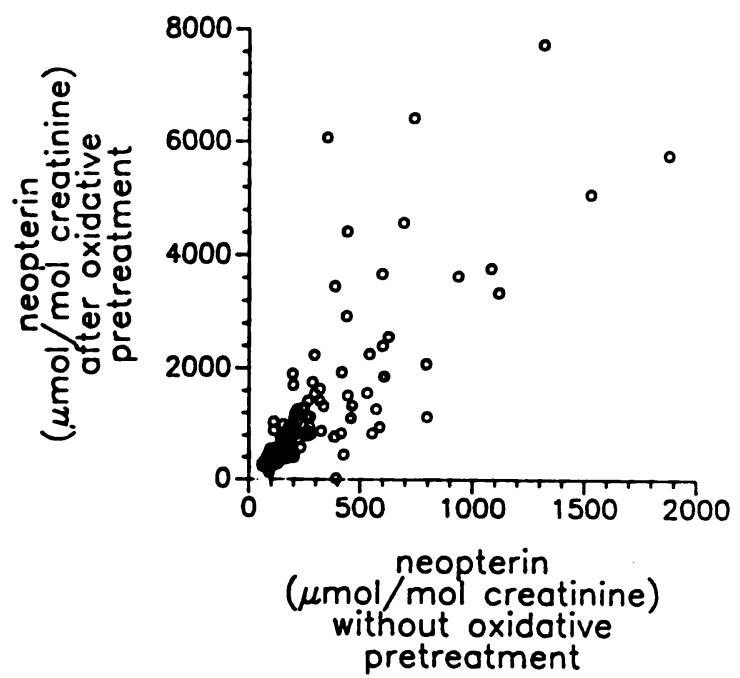

Fig. 1. Correlation between concentrations of neopterin and total neopterins in urine samples from the $150 \mathrm{HIV}-1-$-seropositive and -seronegative subjects studied

$R_{8}=0.838(P<0.0001)$ by Spearman rank correlation

total neopterins (Figure 1). The correlation was also significant between neopterin and 7,8-dihydroneopterin concentrations $(\mathrm{Rs}=0.714, P<0.0001)$.

In the HIV-1-seropositive individuals, all neopterin variables correlated inversely to $\mathrm{CD4}^{+} \mathrm{T}$-cell counts and $\mathrm{CD4}^{+} / \mathrm{CD8}^{+} \mathrm{T}$-cell ratios but not to $\mathrm{CD8}^{+} \mathrm{T}$-cell counts (Table 2). No such correlation was found in the seronegative subjects.

\section{Discussion}

In this study urinary neopterin concentrations correlated significantly with the concentrations of total neopterins (Figure 1), both in healthy anti-HIV-1-seronegative homosexuals and in homosexuals with established HIV-1 infection. Concentrations of 7,8-dihydroneopterin averaged three-fold the neopterin concentrations. However, the ratio of total neopterins to 7,8-dihydroneopterin in some samples was close to 1. Abnormally low amounts of 7,8-dihydroneopterin in samples may be explainable by degradation of the compound during sample-handling procedures. The 6-substituted 7,8-dihydropterin derivatives decompose rapidly to 7,8-dihydroxanthopterin if not properly protected from light and air (13). However, samples for measurement of total neopterins were handled with the necessary caution. In contrast, neopterin is much more stable if kept protected from light (14). Particularly high concentrations of total neopterins in some samples further argue for variations in the concentrations of neopterin derivatives towards relatively lower and higher 7,8-dihydroneopterin content.

Table 1. Concentrations of Neopterin, Total Neopterins, and 7,8-Dihydroneopterin in Urine of Homosexuals with and without HIV-1 Antibody

Madien, and 25-75 percentib range, umol per mole creatinino

Neopterin"

Total neopterins after oxidation

7,8-Dihydroneopterin (total neopterins minus neopterin)"

- $P<0.0001$, Kruska1-Wallis test for differences between groupe.

\begin{tabular}{|c|c|c|}
\hline $\begin{array}{l}\text { HIV-1 seronegattive } \\
(n=73)\end{array}$ & $\begin{array}{l}\text { HIV-1 ceroposittive } \\
\text { without aDe }(n=60)\end{array}$ & $\begin{array}{l}\text { HIV-1 seropocittive } \\
\text { with ADS }(n=8)\end{array}$ \\
\hline 112, 91-144 & $248,194-416$ & $940, \quad 572-1324$ \\
\hline $418,326-486$ & $958,793-1559$ & $2869,2162-4416$ \\
\hline $298,224-368$ & $713,558-1152$ & $2009,1493-3110$ \\
\hline
\end{tabular}




\begin{tabular}{|c|c|c|c|}
\hline \multirow[b]{2}{*}{ T-colls } & \multicolumn{3}{|c|}{ Rs (Spearman rank correlation cosficient) } \\
\hline & Neopterin & Total neopterins & 7,8-Dihydroneopterin \\
\hline \multicolumn{4}{|c|}{ HIV-1-seropositive subjects } \\
\hline \multirow{2}{*}{$\mathrm{CD}^{+}$} & -0.445 & -0.405 & -0.370 \\
\hline & $(0.0001)^{a}$ & $(0.0005)$ & $(0.0016)$ \\
\hline \multirow[t]{2}{*}{$\mathrm{CD8}^{+}$} & -0.023 & -0.001 & -0.023 \\
\hline & (n.s.) & (n.s.) & (n.s.) \\
\hline \multirow[t]{2}{*}{$\mathrm{CD}^{+} / \mathrm{CD}^{+}$} & -0.507 & -0.525 & -0.479 \\
\hline & $(<0.0001)$ & $(<0.0001)$ & $(<0.0001)$ \\
\hline \multicolumn{4}{|c|}{ HIV-1-seronegative subjects ${ }^{\circ}$} \\
\hline $\mathrm{CD}^{+}$ & -0.026 & 0.014 & 0.008 \\
\hline $\mathrm{CD8}^{+}$ & -0.056 & -0.025 & -0.039 \\
\hline $\mathrm{CD}^{+} / \mathrm{CD}^{+}$ & -0.078 & -0.076 & -0.075 \\
\hline
\end{tabular}

- Pvalues given in parentheses; n.s., not significant. ' All comparisons not significantly different.

All neopterin variables (i.e., neopterin, total neopterins, and 7,8-dihydroneopterin) discriminated well between HIV-1 serological status in these subjects. The HIV-1seropositive men showed a close inverse correlation between neopterin concentrations and $\mathrm{CD}^{+} \mathrm{T}$-cell numbers and $\mathrm{CD}^{+} / \mathrm{CD}^{+} \mathrm{T}$-cell ratios (Table 2). This relationship did not exist in the HIV-1-seronegative men, confirming earlier results (7).

Our present results extend this observation to 7,8-dihydroneopterin. Concentrations of total neopterins and 7,8dihydroneopterin were also found to inversely correlate with $\mathrm{CD4}^{+} \mathrm{T}$-cell numbers and $\mathrm{CD4}^{+} / \mathrm{CD8}^{+} \mathrm{T}$-cell ratios in the HIV-1-seropositive men. Elsewhere we have recently shown that neopterin $(8,15)$ and total neopterins $(8)$ are of similar value in predicting the onset of AIDS in HIVseropositive homosexual men.

Neopterin is produced and secreted by human macrophages on stimulation with $\gamma$-interferon (5). Recently, increased circulating $\gamma$-interferon was found to parallel the course of HIV-1 infection, with AIDS patients having highest concentrations of $\gamma$-interferon in serum (16). We assumed that increased concentrations of 7,8-dihydroneopterin also reflect macrophage activity, in line with the observation that macrophages stimulated by $\gamma$-interferon produce neopterin and 7,8-dihydroneopterin in parallel (unpublished data). However, the concentrations of 7,8dihydroneopterin in vitro may be underestimated because it will be partly destroyed during the culture period of three days. Therefore, unless care is taken to ensure recovery of dihydroneopterin, neopterin measurements may be more reliable estimates of total neopterins in in-vitro systems.

Our data indicate that concentrations of neopterin and total neopterins are of almost equal potential for clinical diagnosis. Statistical evaluation in HIV-1-seropositive individuals demonstrates a close correlation between concentrations of neopterin and total neopterins in urine. We speculate that the same associations can be found in other conditions associated with activation of cellular immunity. The same relation between neopterin and total neopterins can be expected in serum samples. One may prefer to use urine instead of serum samples because it is less infectious and collection of samples is more convenient for patients when they are not bled for other reasons. The diagnostic quality of neopterin appears to be independent from the choice of serum or urine as sample. However, measurement of total neopterins by oxidation of 7,8-dihydroneopterin to neopterin necessitates more strictly controlled sample collection and handling to avoid degradation of the 7,8dihydro derivative. In addition, this sample preparation is more time consuming and laborious than that for direct quantification of neopterin. For quantification of naturally occurring neopterin, samples are stable at room temperature for three days (17), which means that samples can be mailed to specialized diagnostic laboratories.

This work was financially supported by the Austrian Research Funds "Zur Förderung der Wissenschaftlichen Forschung," p 6922M.

\section{References}

1. Danks DM. Pteridines and phenylketonurias. $J$ Inherited Metab Dis 1978;1:47-8.

2. Kaufman S. The structure of phenylalanine hydroxylation cofactor. Proc Natl Acad Sci USA 1963;50:1085-93.

3. Kaufman $S$. The metabolic role of tetrahydrobiopterin. In: Cooper BA, Whitehead VM, eds. Chemistry and biology of pteridines. Berlin-New York: Walter de Gruyter, 1986:185-200.

4. Wachter H, Fuchs D, Hausen A, Reibnegger G, Werner ER. Neopterin as marker for activation of cellular immunity: immunological basis and clinical application [Review]. Adv Clin Chem 1989;27:81-141.

5. Fuchs D, Hausen A, Reibnegger G, Werner ER, Dierich MP, Wachter H. Neopterin as a marker for activated cell-mediated immunity: application in HIV-infection [Review]. Immunol Today 1988;9:150-5.

6. Wachter H, Fuchs D, Hausen A, et al. Elevated urinary neopterin levels in patients with the acquired immunodeficiency syndrome (AIDS). Hoppe Seylers Z Physiol Chem 1983;364:1345-6.

7. Fuchs D, Banekovich M, Hausen A, et al. Neopterin estimation compared with the ratio of T-cell subpopulations in persons infected with human immunodeficiency virus 1 . Clin Chem 1988;34:2415-7.

8. Krämer A, Viktor SZ, Fuchs D, et al. Neopterin: a predictive marker of acquired immunodeficiency syndrome in human immunodeficiency virus infection. J AIDS 1989;2:291-6.

9. Werner ER, Bichler A, Daxenbichler G, et al. Determination of neopterin in serum and urine. Clin Chem 1987;33:62-6.

10. Abita JP, Cost H, Milstien S, Kaufman S, Saimot G. Urinary neopterin and biopterin levels in patients with AIDS and AIDSrelated complex [Letter]. Lancet 1985;ii:51.

11. Goedert JJ, Biggar RJ, Melbye M, et al. Effect of $T_{4}$ count and cofactors on AIDS incidence in homosexual men infected with human immunodeficiency virus. J Am Med Assoc 1987;257:331-3. 12. Levine RA, Milstien S. The ratio of reduced to oxidized neopterin and biopterin in human fluids: significance to the study of human disease. In: Wachter H, Curtius HC, Pfleiderer W, eds. Biochemical and clinical aspects of pteridines. Berlin-New York: Walter de Gruyter, 1984:277-84.

13. Rembold H, Metzger H, Gutensohn W. Catabolism of pteridine cofactors. Biochim Biophys Acta 1971;230:117-26.

14. Werner ER, Fuchs D, Hausen A, Reibnegger G, Wachter H. Simultaneous determination of neopterin and creatinine in serum with solid-phase extraction and on-line elution liquid chromatography. Clin Chem 1988;34:466-7.

15. Fuchs D, Spira TJ, Hausen A, et al. Neopterin as predictive marker for disease progression in human immunodeficiency virus type 1 infection. Clin Chem 1989;35:1746-9.

16. Fuchs D, Hausen A, Reibnegger $G$, et al. Interferon-gamma concentrations are increased in sera from individuals infected with human immunodeficiency virus type 1. J AIDS 1989;2:158-62.

17. Fuchs D, Hausen A, Reibnegger G, Wachter H. Automatized routine estimation of neopterin in human urine by HPLC on reversed phase. Op. cit. (ref. 12): Vol. 1, 1982;67-79. 